Hamade, L.

CUSTOMER SATISFACTION WITH ONLINE FOOD AND GROCERY SHOPPING SERVICE DURING COVID-19 IN

LEBANON

\title{
CUSTOMER SATISFACTION WITH ONLINE FOOD AND GROCERY SHOPPING SERVICE DURING COVID-19 IN LEBANON
}

\author{
Layal Hamade \\ Bucharest University of Economic Studies, Bucharest, Romania \\ Layal.hamade@liu.edu.Ib
}

\begin{abstract}
Covid-19 pandemic has changed companies' strategies to reach their customers. To combat economic downturns due to quarantines and worldwide country closures, stores had to establish a new method to satisfy their customer needs such as adopting online food and grocery ordering and delivery systems. The aim of this research is to give an overview over food and grocery online shopping in different countries through secondary data collection and to analyse Lebanese customers' food and grocery online shopping behaviour before and during Covid-19 pandemic through primary data collection. To assess the Lebanese market and the rate of satisfaction with food and grocery online ordering and delivery, an online survey was distributed to 300 participants using random sampling technique. Results showed that Lebanese customers have increased their food and grocery online ordering through WhatsApp during Covid-19 pandemic and customers are satisfied with the overall service quality of delivered food, grocery, and with delivery time.
\end{abstract}

Keywords: Covid-19, delivery, food, grocery, online shopping.

DOI: https://doi.org/10.24818/beman/2021.S.I.2-05

\section{INTRODUCTION}

The beginning of the Covid-19 pandemic has disturbed most parts of life, including the way individuals access products. Government-commanded lockdowns have kept shoppers at home, forestalling ordinary shopping designs, and numerous physical organizations have shut down (Unnikrishnan \& Figliozzi, 2020). In the new time, particularly in this new standard, innovation has changed the world into another marvel by changing human conduct into an advanced way that made it easy on individuals, from getting up in the early morning until getting function just as providing food (Ramli, et al., 2021).

Among many assembling areas, the food and grocery industries are one of the dominating businesses, through which essential requirements for human advancement are essential. Since food is a key prerequisite for human sustenance, typical activities ought to be supported to take care of individuals during pandemic-like circumstances. All things considered; gardening gives $83 \%$ of the food devoured by people. 
Hamade L.

The food industry is a dynamic, worldwide structure of assorted organizations that give most of the world's food. In 2020, a report uncovered that the food and drink industries are one of the quickest developing on the planet (Memon, et al., 2021).

Because of far reaching preclusions on eating inside cafés, interest for eatery food has diminished drastically since the start of the pandemic, and eateries unfit to offer take-away services have shut (Mohammed, 2020). The subsequent change in consumers' demand of food dining outside their houses as in restaurants versus the food bought at stores, supermarkets and some other stores has brought about deficiencies and declining stock levels of some food items (Uhler, 2020)

For some shoppers, an answer for a portion of the difficulties made by COVID-19 is home delivery. Webbased businesses and house deliveries can be an advantageous answer for labourers compelled to work distantly just as numerous different gatherings, for example, guardians that need to shuffle both work and nurturing requests or gatherings in danger of creating genuine COVID-19 wellbeing-related inconveniences (Unnikrishnan \& Figliozzi, 2020).

For instance, in USA, just over portion of food uses before the pandemic where from eating houses (Saksena et al. 2018). With eating houses alternatives restricted to take-away during covid-19 in a significant part of the U.S., grocery and drink stores demand expanded over 25\% in March 2020 (Redman 2020). Moreover, March supermarket deals expanded by $20 \%$ in the U.K., establishing a four-week deals history (Mattinson 2020)

The purpose of this study is assessing Lebanese customer satisfaction with the overall food and grocery delivery services during Covid-19 pandemic, their frequency of shopping, their concerns with food and grocery delivery, and how Covid-19 affected home food and grocery ordering and delivery service. To accomplish this goal, the following research questions are to be addressed:

- What is the rate of satisfaction of Lebanese customers with delivery time?

- What is the rate of satisfaction of Lebanese customers with online delivered food and grocery overall service quality?

Moreover, as supportive data in Lebanon related to delivery services and customer satisfaction is limited, this research will assist in supporting customer service strategies after evaluating their delivery service and collecting customer feedback. In addition, Lebanese customer feedback will conclude on customers' needs, the basic for setting any strategy which can be used for future research.

\section{LITERATURE REVIEW}

Alaimo, Fiore, \& Galati (2020) distributed an online questionnaire on 248 participants during Covid-19 in Italy. It revealed that customers were satisfied with their online food ordering as they find it and easy way to 


\section{LEBANON}

get their food without the bother to visit stores and interact with others. In addition, $74.6 \%$ stated that they were medium to highly satisfied with ordering food online.

According to Klinbeil et al. (2021), a survey filled by 1074 respondents in Lebanon, Jordan, and Tunisia showed that out of 346 Lebanese respondents, 236 were females. $81.9 \%$ of the Lebanese participants were between the age of 25 and 54 years old. Moreover, in Lebanon, when asked about the frequency of food shopping during Covid-19 pandemic, 39.6\% stated that they shop once a week, $24.3 \%$ two-three times a week, $24 \%$ less than once a week, $0.6 \%$ three to seven times a week, and $11.5 \%$ depended totally on home deliveries. When asked whether they will re-purchase from the same places after the pandemic is over, the results were $41.6 \%$ of Lebanese respondents will continue shopping from the same places, $28 \%$ said no, and $30.4 \%$ said maybe.

According to Laguna et al. (2020), a questionnaire sent online to 362 Spanish participants stated that $70 \%$ were female and $30 \%$ were male. It showed that before Covid-19 pandemic, $96.6 \%$ used to purchase their food from supermarkets, $39.21 \%$ from small shops, $7.56 \%$ online. In addition, $50 \%$ used to shop twice per week and 35\% weekly. However, During Covid-19 pandemic, 76.5\% were shopping weekly, $13.65 \%$ twice per week, and $1.12 \%$ daily.

According to Chen et al. (2021), a questionnaire filled by 156 respondents from Wuhan city, China, revealed that $53.8 \%$ were females, $46.2 \%$ were males, and $80.1 \%$ were between the age of $26-45$ years old. In addition, it was shown that before Covid- $19,65.38 \%$ used to shop fresh food online and $33.33 \%$ used to do so at least once a week, $30.39 \%$ several times a week, and $16.67 \%$ less than once a month. However, during Covid-19, 38.46\% shopped once a week, 39.74\% shopped several times a week, and $12.18 \%$ once every two weeks. Moreover, the waiting time to receive the online order during Covid- 19 was $27.56 \%$ less than 12 hours, $34.62 \%$ wait $12-24$ hours, and $29.49 \%$ wait $24-48$ hours.

According to Park, Brumberg, \& Yonezawa (2020), a survey distributed to shoppers in different USA regions concluded that physical store grocery shopping decreased from $85.3 \%$ before Covid-19 pandemic to $72.4 \%$ during Covid-19. Online orders increased from $8.4 \%$ before Covid- 19 to $21.1 \%$ during Covid-19 due mainly to the increase in the online shoppers during Covid- 19 from $30.8 \%$ to $45.5 \%$ and to the rise in the quantities purchased. Furthermore, before Covid-19 pandemic, males in urban cities, who are younger than 65 years old were the most to purchase groceries online. However, during Covid-19 pandemic, married females represented the main segment to shop groceries online.

Robinson et al. (2020) researched consumer online purchase behaviour in United States and he revealed that before Covid- 19 , customers purchased their food $90 \%$ from groceries, $68 \%$ restaurant dining, and $64 \%$ deliveries. During Covid-19, grocery physical store shopping decreased by $18 \%$ and grocery delivery 
Hamade L.

increased by $62 \%$. In addition, during Covid-19, $65 \%$ stated that they had difficulty finding the food types they were asking for and $58 \%$ said that they had to go through different stores to get all their products.

According to Dospinescu, et al. (2020), a lot of factors contribute to the reputation of delivery companies where it was proven that the food delivered quality, the price, the menu diversity, food taste, the perception of companions, and the quality of the electronic application have a statistically significant effect on reputation.

\section{RESEARCH QUESTION}

Covid-19 pandemic and recurrent lockdowns have forced people to find alternative ways to shop their products. Food and grocery stores have offered its customers a delivery service to make products available to Lebanese people without the need to go out. In addition, through conducting this study, limited data was available to support my research and enrich it with feedback regarding customer satisfaction of delivery service in Lebanon during Covid-19 pandemic. This study will address the rate of customer satisfaction with delivery time and delivered food and grocery service quality, customers concern with the delivery service, and the frequency of ordering food and grocery.

Research questions to be answered:

RQ1: what is the rate of satisfaction of Lebanese customers with delivery time?

RQ2: What is the rate of satisfaction of Lebanese customers with online delivered food and grocery service quality?

\section{RESEARCH METHODS}

To analyse customers' satisfaction rate with food and grocery online delivery service in Lebanon, a quantitative descriptive study was adopted. An online survey was distributed via social media including 15 questions, demographic questions and customers' perception and behaviour towards food and grocery delivery in Lebanon. The sampling technique used was simple random sampling and a total of 300 participants responded to the online survey using Google Forms and data was collected through February and March 2021. Moreover, secondary data was gathered through analysing articles and other research data.

\section{RESULTS}

- Age

An approximately equal percentage of participants between the ages of 26-32 years, 33-40 years, and 4148 years have submitted their feedback. These ages represent the major group who may order food and grocery from home (figure 1). 
- 26-32 years

- 33-40 years

- 41-48 years

- 49-56 years

FIGURE 1. PARTICIPANTS' AGE

Source: Author

- Gender

According to figure 2, female participants were more than male participants. In the Lebanese culture, females take more responsibility of securing food and groceries for their homes.

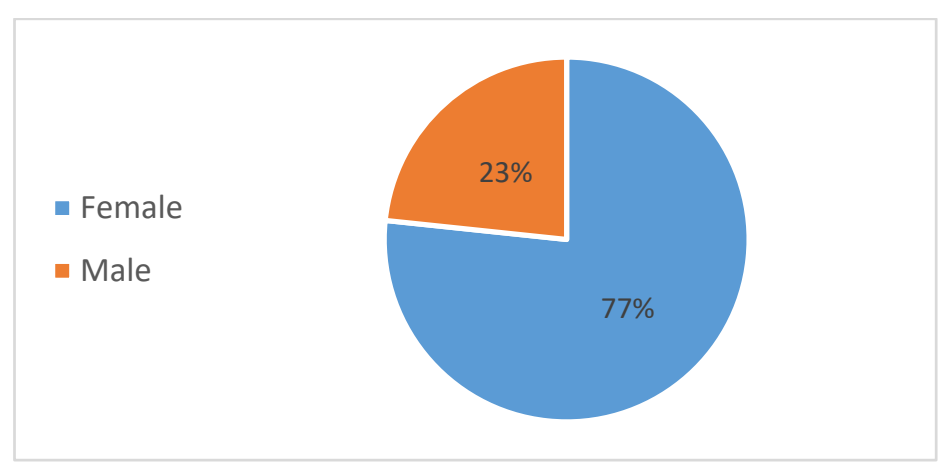

FIGURE 2. PARTICIPANTS' GENDER

Source: Author

- Before Covid-19 pandemic, did you shop for groceries/food online?

Before Covid-19, the majority did not purchase their food and groceries online (Figure 3). Most of the participants were getting their basic needs through visiting physical stores as it was safe to engage with people and customers prefer to surf, interact, and choose their products' brand, quality, and price as they need. 
Hamade L.

CUSTOMER SATISFACTION WITH ONLINE FOOD AND GROCERY SHOPPING SERVICE DURING COVID-19 IN LEBANON

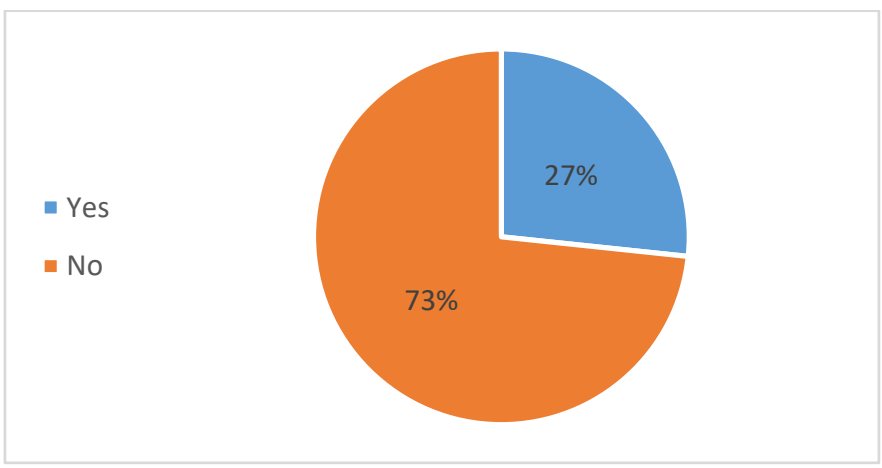

FIGURE 3. PERCENTAGE ONLINE FOOD/GROCERY SHOPPING BEFORE COVID-19

Source: Author

- During Covid-19, did your food online purchases increased?

During Covid-19, most of the participants were shopping their food online (figure 4). More people shifted to use online ways of communication with food stores to get their necessities due to quarantines and social distancing procedures forced by Lebanese government. In addition, physical stores, as a way of survival, established their online methods to keep their customers.

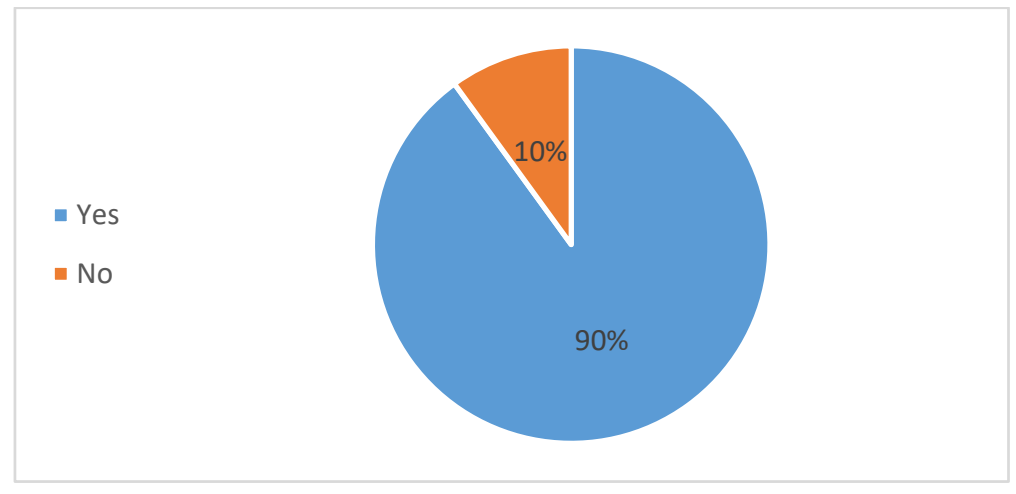

FIGURE 4. PERCENTAGE FOOD ONLINE SHOPPING DURING COVID-19

Source: Author

- During Covid-19, did your grocery online purchases increased?

During Covid-19, higher percentage of the participants were shopping grocery online (figure 5). This is due to the diversity in grocery quality and customers' preference to choose their groceries. In Lebanon, groceries were allowed to open and people had the choice to wait outside the stores, in their cars, and ask for their products from employees standing outside to take orders. 
Hamade, L.

CUSTOMER SATISFACTION WITH ONLINE FOOD AND GROCERY SHOPPING SERVICE DURING COVID-19 IN

LEBANON

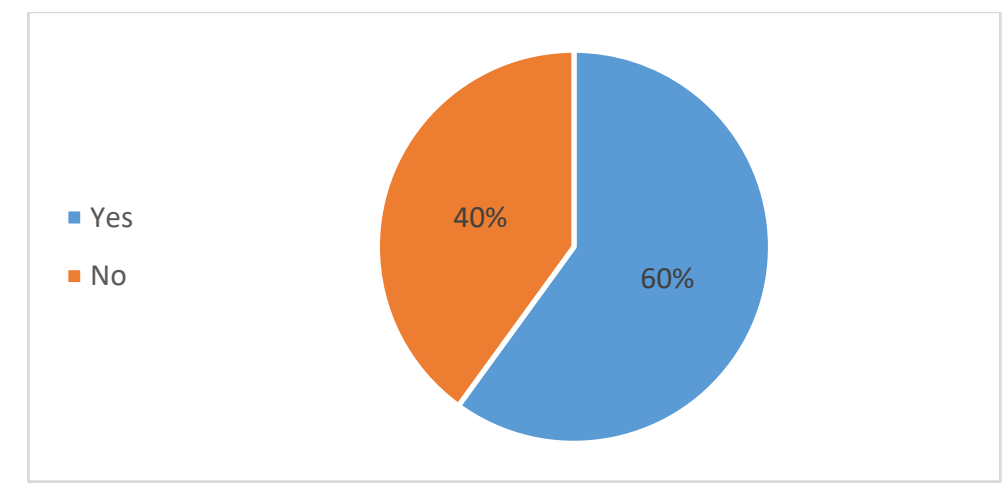

FIGURE 5. PERCENTAGE GROCERY ONLINE SHOPPING DURING COVID-19

Source: Author

- During Covid-19, how often did you shop grocery online?

As shown in figure 6, approximately half of the participants were shopping groceries twice per week. As groceries have low self-life, fresh products are always preferrable. Therefore, in Lebanon, customers prefer to more groceries more often than stocking them at home and risking quality and freshness.

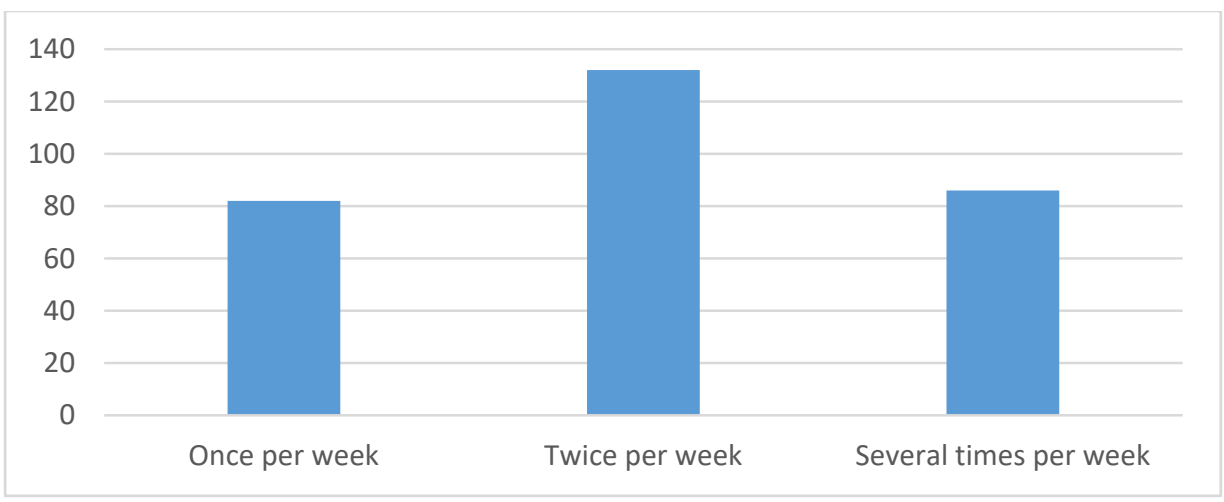

FIGURE 6. FREQUENCY GROCERY ONLINE SHOPPING DURING COVID-19

Source: Author

- During Covid-19, how often did you shop food online?

Most participants were shopping food online several times a week (figure 7). Participants shopped more food online than groceries. Food is considered a more consumable product than groceries and in Lebanon, customers consume at least 3 meals per day. 
Hamade L.

CUSTOMER SATISFACTION WITH ONLINE FOOD AND GROCERY SHOPPING SERVICE DURING COVID-19 IN LEBANON

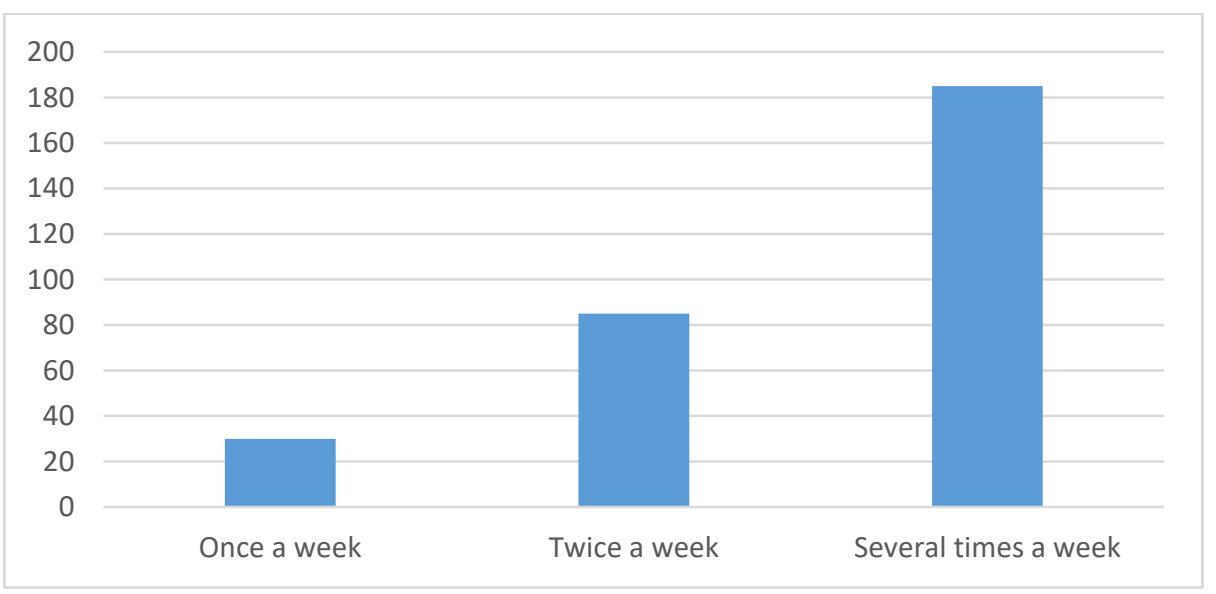

FIGURE 7. FREQUENCY FOOD ONLINE SHOPPING DURING COVID-19

Source: Author

- What are your concerns when buying your grocery online?

The main concerns when shopping grocery online were the product availability, product freshness, product choice, and returns (figure 8). The first concern was product availability at the store customers' contact to avoid having to get their products from different places. The second concern was product freshness as those who order online didn't have the chance to see their products and check its quality, and the third concern was the product choice as even with groceries there are different types of tomatoes, cucumber, apples, etc. and customers shopping online were not able to see what choices groceries had.

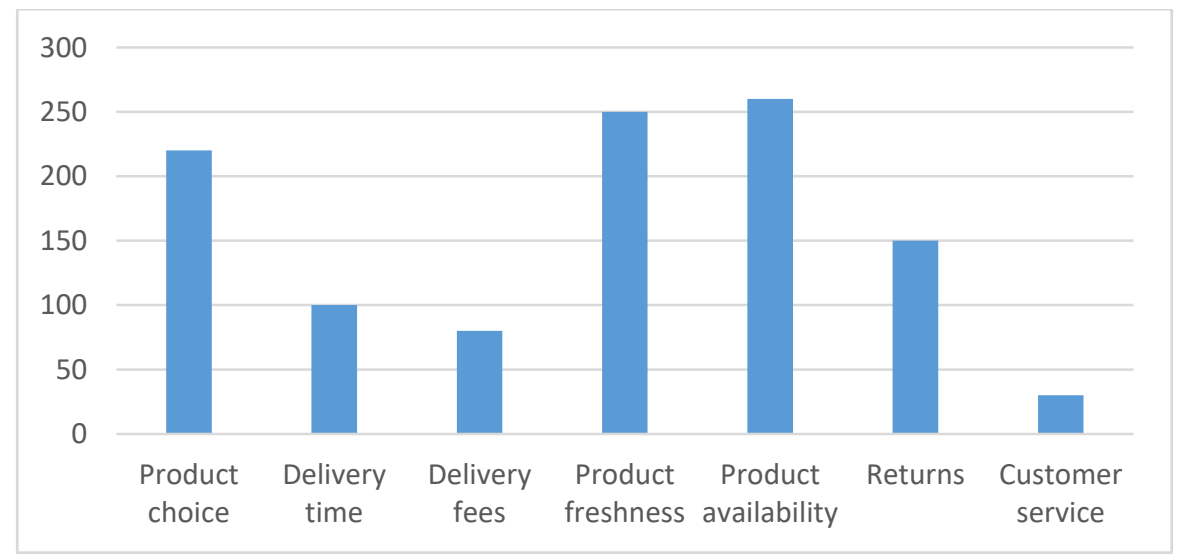

FIGURE 8. CUSTOMERS' CONCERNS OF GROCERY ONLINE SHOPPING

Source: Author

- What are your concerns when buying your food online? 
Hamade, L.

CUSTOMER SATISFACTION WITH ONLINE FOOD AND GROCERY SHOPPING SERVICE DURING COVID-19 IN

LEBANON

The main concerns when purchasing food online were returns, product availability, delivery time, and product choice (figure 9). As many brands are available on shelves with different prices, the customer may not know what brands are available with their prices and may get surprised with the price or quality delivered. If the store accepted to return, then the customer will have to ask for the product from another store and wait additional time. In addition, as more customers are ordering online then delivery personnel might need more time to deliver products.

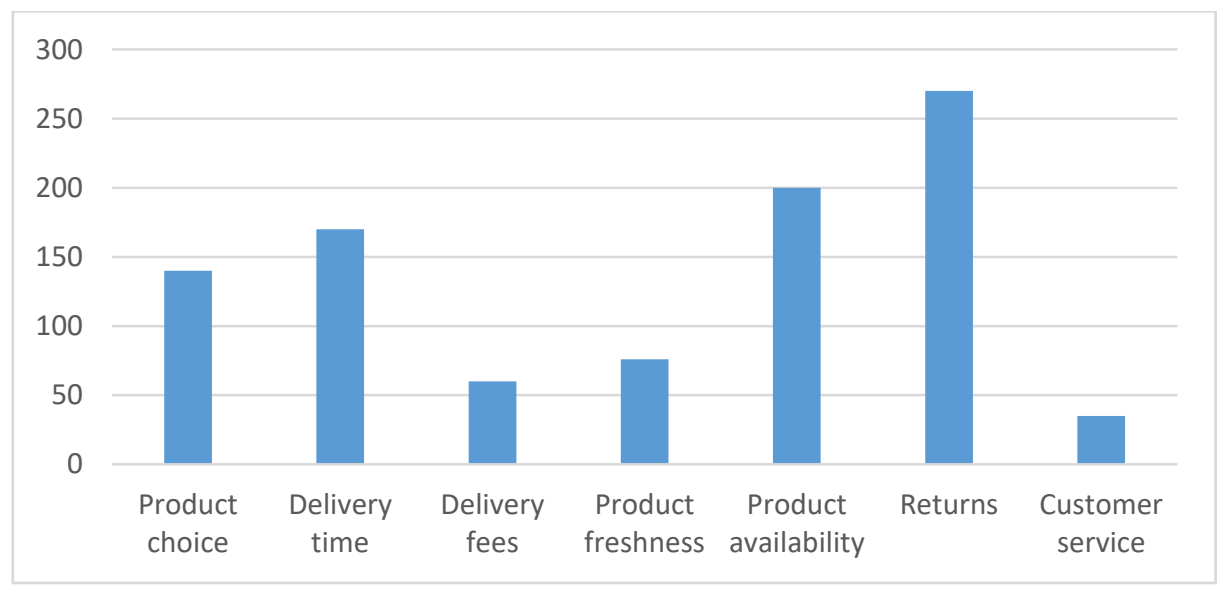

FIGURE 9. CUSTOMERS' CONCERNS OF FOOD ONLINE SHOPPING DURING COVID-19

Source: Author

- How do your order your food products?

Most of the respondents shopped their food through WhatsApp followed by phone calls (figure 10). Before covid-19, no online applications were available. The emergence of covid-19 and the need for an immediate method to accept customers' orders, made stores choose the easiest way to communicate with customers which is WhatsApp.

- WhatsApp

- Phone call

- Online

application/Website

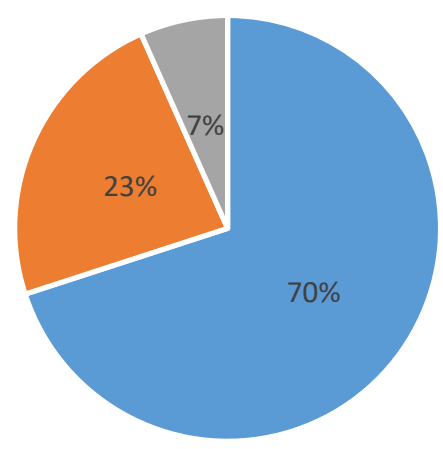


Hamade L.

CUSTOMER SATISFACTION WITH ONLINE FOOD AND GROCERY SHOPPING SERVICE DURING COVID-19 IN LEBANON

\section{FIGURE 10. CUSTOMERS' FOOD ORDERING METHODS}

Source: Author

- How do your order your groceries?

Groceries were mainly ordered through WhatsApp and phone calls (figure 11). Grocery stores in Lebanon are small and not considered huge companies to set online applications. As in food ordering, grocery stores depended on WhatsApp and phone calls to make their grocery delivered home.

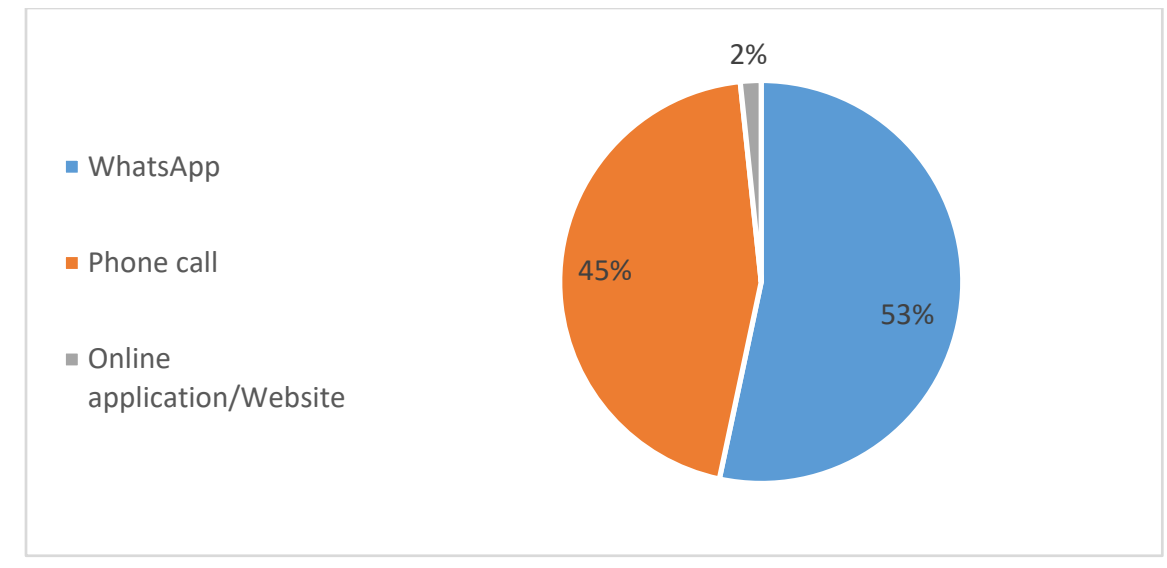

FIGURE 11. CUSTOMERS' GROCERY ORDERING METHODS

Source: Author

- How much time does it take to receive your order?

Most deliveries took between 40-60 minutes and this is considered an appropriate fair time to prepare and deliver customers' necessities (figure 12).

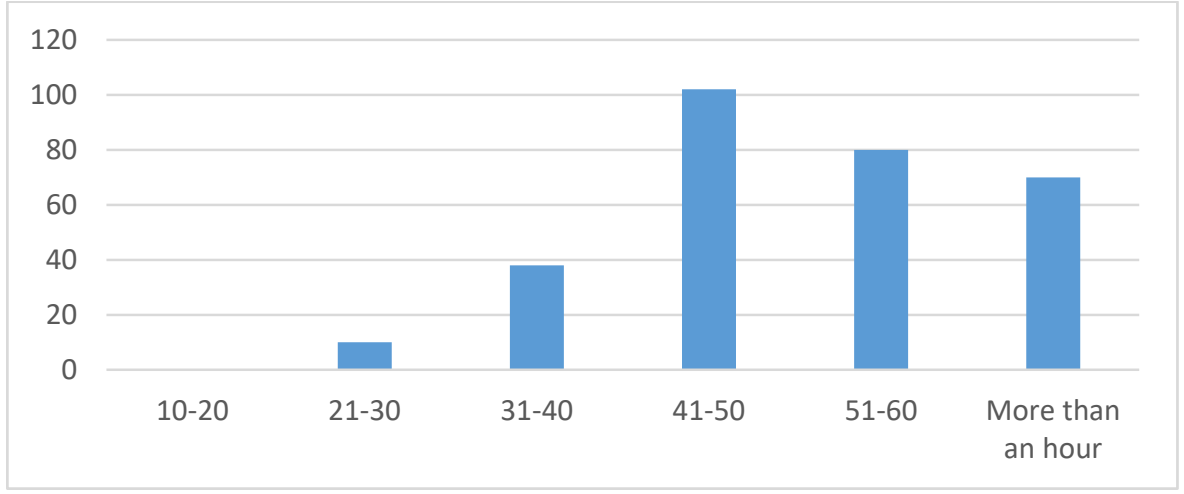

FIGURE 12. APPROXIMATE DELIVERY TIME

Source: Author

- Rate your satisfaction with delivery time. 
Hamade, L.

CUSTOMER SATISFACTION WITH ONLINE FOOD AND GROCERY SHOPPING SERVICE DURING COVID-19 IN

LEBANON

When measuring customers' rate of satisfaction depending on food and grocery delivery time, most of the respondents were satisfied and only $27 \%$ were dissatisfied (figure 13). Thus, customers were satisfied with the delivery time and it was not one of their main concerns.

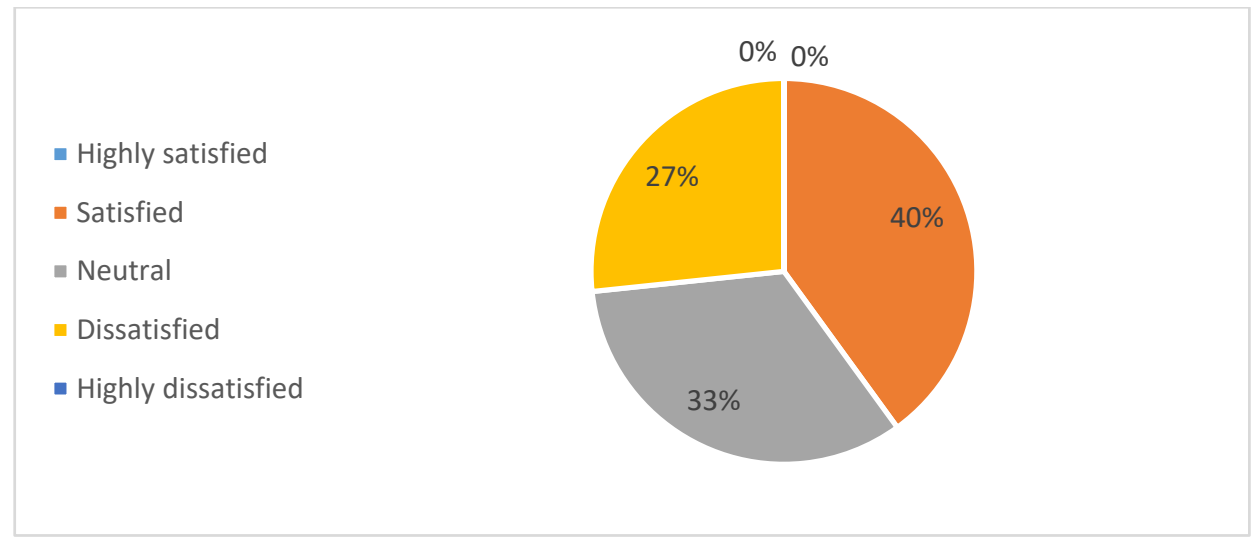

FIGURE 13. SATISFACTION RATE WITH DELIVERY TIME

Source: Author

- Rate your satisfaction with delivered food overall service quality.

Measuring the rate of customers' satisfaction through assessing delivered food service quality, $23 \%$ were highly satisfied, $43 \%$ were satisfied, $27 \%$ were neutral, and $7 \%$ were dissatisfied (figure 14). Therefore, the delivered food was meeting the expectations of the customers and they were satisfied with the food service they were receiving.

- Highly satisfied

- Satisfied

- Neutral

- Dissatisfied

- Highly dissatisfied

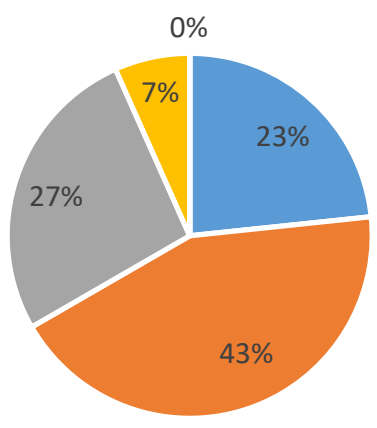

FIGURE 14. RATE OF SATISFACTION WITH DELIVERED FOOD SERVICE QUALITY

Source: Author

- Rate your satisfaction with delivered groceries overall service quality. 
Hamade L.

Assessing the rate of satisfaction with delivered groceries service quality, $15 \%$ highly satisfied, $30 \%$ satisfied, 33\% neutral, 20\% dissatisfied, and $2 \%$ highly dissatisfied (figure 15). Thus, there was a moderate satisfaction with the service quality of groceries delivered home and rate of satisfaction with groceries service quality was lower than that of food.

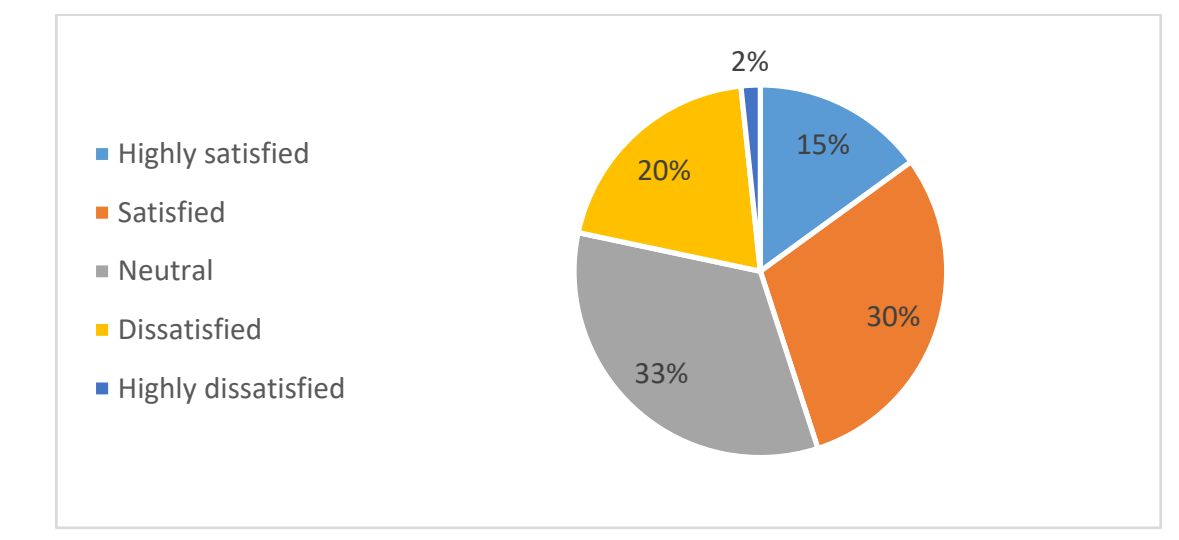

FIGURE 15. RATE OF SATISFACTION WITH DELIVERED GROCERIES SERVICE QUALITY

Source: Author

\section{CONCLUSIONS}

As with Klinbeil et al. (2021) \& Laguna et al. (2020), food and grocery online shopping is more a female task than a male one where most of those who responded were females. Moreover, when comparing food ordering before and during covid-19, Lebanese customers increased their online food shopping behaviour and people were ordering food mostly several times a week with people's wish to save their health, maintain social distancing, and avoid crowds. Such results were supported by Klinbeil at al. (2021) who stated that $63.9 \%$ of his participants shopped food on a weekly basis. However, still people had their concerns. The main concern was product return policy, then product availability, product delivery time, and product choice. As many companies are competing on the store shelves, people usually don't memorize all brands available with their prices. The store employee may send a product different then what is needed by the customer which will cost the customer not only the delivery charge but the time to check the product availability in other store which will increase the time required for customers to get their products. In addition, WhatsApp was mainly used by delivery personnel in food stores to take customers' orders.

On the other hand, $60 \%$ were ordering grocery online which is lower than the food ordering percentage. This is due to people's concern of product availability, freshness, and choice. This was supported by Park, Brumberg, \& Yonezawa (2020) who showed that grocery shopping decreased after Covid-19. Most of the Lebanese customers preferred to get their groceries by their physical presence on the grocery store door to choose their products and this is proved by Robinson et al. (2020) who stated that during covid-19, 
CUSTOMER SATISFACTION WITH ONLINE FOOD AND GROCERY SHOPPING SERVICE DURING COVID-19 IN

LEBANON

$65 \%$ are concerned with finding their product choice and $58 \%$ about their product availability. In addition, ordering frequency was less than that of food ordering as groceries is less consumed than food. The method used to order grocery from home was divided between WhatsApp and phone calls and this depends on the size of the grocery store where usually bigger stores use more WhatsApp than small ones.

Furthermore, most deliveries, $60.6 \%$, took up to 60 minutes to be delivered which is fair enough if we take into consideration the increase in people online orders, the companies' infrastructure which may not be big enough to serve all its customers immediately and the sudden emergence of covid-19 restrictions which was not considered within the strategies of food and grocery store. On the other hand, when compared to chen et al. (2021) study, $64.11 \%$ received their deliveries after 12 hours. That explains why the Lebanese customers were satisfied with this delivery time frame and only $27 \%$ stated that they were dissatisfied. Moreover, customers were satisfied with the overall service quality of delivered food and groceries; however, the percentage of dissatisfaction with groceries $(22 \%)$ was higher than that of food $(7 \%)$ and this is interpreted by the customers' concerns who pinpointed their worries towards products' availability, freshness, and choice.

According to the stated results, it is recommended by businesses to add online applications for Lebanese customers where they can look for what they need, check its availability, prices, description, and then order it online. In addition, stores should set easy return/exchange policies to diminish customers' concerns and to encourage them to put their orders.

The limitation of this research is the presence of economic recession and inflation in Lebanon which can affect customers' concerns. In addition, quantity ordered and frequency of ordering may differ as people may find it hard to shop in large quantities all at once with price inflation and may prefer to increase the frequency of purchasing versus decreasing the quantity. Moreover, the number of participants is not large enough to reflect the whole market and more demographic questions could be asked such as income and location to be easier to understand each region or segment.

On the other hand, the future directions that were identified are as following: the analysis of food/grocery stores and businesses, the analysis of different variables that might affect the delivery service quality, and the construction of a quantitative analysis linking different socio-demographic factors to the perception of delivery service quality.

\section{REFERENCES}

Alaimo, L., Fiore, M., Galalti, A. (2020). How the Covid-19 Pandemic Is Changing Online Food Shopping 
Hamade L.

CUSTOMER SATISFACTION WITH ONLINE FOOD AND GROCERY SHOPPING SERVICE DURING COVID-19 IN LEBANON

Human Behaviour in Italy. Sustainability. 12, pp. 9594; doi:10.3390/su12229594

Chen, J., Zhang, Y., Zhu, S., Liu, L. (2021). Does COVID-19 Affect the Behavior of Buying Fresh Food?

Evidence from Wuhan, China. International Journal of Environmental Research and Public Health,

18, pp. 4469. https://doi.org/10.3390/ ijerph18094469

Dospinescu, N., Dospinescu, O., Tatarusanu, M. (2020). Analysis of the Influence Factors on the

Reputation of Food-Delivery Companies: Evidence from Romania. Sustainability, 12, 4142; doi:10.3390/su12104142

Figliozzi, M., Unnikrishnan, A. (2021). Home-deliveries before-during COVID-19 lockdown: Accessibility, environmental justice, equity, and policy implications. Transportation Research. Part D 93, pp. 102760

Klinbeil, D. et al. (2021). An on-line survey of the behavioral changes in Lebanon, Jordan and Tunisia during the COVID-19 pandemic related to food shopping, food handling, and hygienic practices. Food Control. 125, pp. 107934

Laguna, L., et al. (2020). The impact of COVID-19 lockdown on food priorities. Results from a preliminary study using social media and an online survey with Spanish consumers. Food Quality and Preference, 86, pp. 104028

Mattinson, A. (2020). Coronavirus demand surge supercharges grocery industry growth. The Grocer. https://www.thegrocer.co.uk/finance/coronavirus-demand-surge-superchargesgrocery-industrygrowth/603530.article.

Memon, S., Pawase, V., Pavase, T., Soomro, M. (2021). Investigation of COVID-19 Impact on the Food and Beverages Industry: China and India Perspective. Foods. 10, pp. 1069. https://doi.org/ 10.3390/foods 10051069 .

Mohammed, R. (2020). How restaurants can survive right now. Harvard Business Review. March 26. Accessed on May 26, 2020 at: https://hbr.org/2020/03/howrestaurants-can-survive-right-now.

Park, K., Brumberg, A., Yonezawa, K. (2020). The Covid-19 Shopper: Online Shopping. Department of Applied Economics and Management Cornell University. https://dyson.cornell.edu/wpcontent/uploads/sites/5/2021/01/Covid_Shopper-Online_EB2020-14-VD.pdf

Ramli, N., Ghani, F. A., Nawawi, W., \& Majid, H. (2021). Intention to Use Online Food Ordering Services Among Universities Students During COVID-19 Pandemic. International Journal of Academic Research in Business and Social Sciences, 11(13), pp. 394-405.

Redman, R. (2020). Grocery a bright spot in record March retail sales decline. Supermarket News. https://www.supermarketnews.com/consumer-trends/grocery-bright-spot-recordmarch-retail-salesdecline

Robinson, J., et al. (2020). US Consumer Experiences with Food Access During Covid-19. National Food Access and COVID Research Team. https://jscholarship.library.jhu.edu/bitstream/handle/1774.2/63253/Food\%20Access FINAL11.pdf? sequence $=1$

Saksena, M. J., Okrent, A., M., Anekwe, T. D., Cho, C., Dicken., C., Effland, A. et al. (2018). America's eating habits: food away from home. Economic Information Bulletin, 196.

Uhler, A. (2020). Changes in demand and disrupted supply chains feed into shortages at the store. Marketplace. https://www.marketplace.org/2020/04/13/shortages-at-store-arent-aboutpeoplestocking-up/. 
Hamade, L.

CUSTOMER SATISFACTION WITH ONLINE FOOD AND GROCERY SHOPPING SERVICE DURING COVID-19 IN LEBANON 